CORDINI, Nicolás. "Jurisdicción regional y delitos de organización: diversas alternativas".

Polít. crim. Vol. 12, No 23 (Julio 2017), Art. 2, pp. 56-77.

[http://www.politicacriminal.cl/Vol_12/n_23/Vol12N23A2.pdf]

\title{
Jurisdicción regional y delitos de organización: diversas alternativas
}

\section{Regional jurisdiction and organised offences: several alternatives}

\author{
Dr. iur. Nicolás S. Cordini, LL.M. \\ Doctor y Magister en Derecho, Becario Posdoc CONICET en el Instituto A. Gioja, \\ Facultad de Derecho - Universidad de Buenos Aires; Profesor adjunto de Derecho Penal I \\ de la Facultad de Ciencias Jurídicas y Sociales - Universidad Nacional del Litoral (Santa \\ $\mathrm{Fe}$ - Argentina). \\ ncordini@fcjs.unl.edu.ar
}

\section{Resumen}

La lucha contra las organizaciones criminales constituye un eje central de la política criminal de los países de la región. Estas organizaciones han alcanzado una dimensión global y han escapado al control de las instituciones nacionales. Frente a este fenómeno, los Estados nacionales se encuentran en una situación de dificultad de desplegar una política criminal efectiva. Frente a ello, se ha planteado la necesidad de crear una Corte Penal Regional contra el Crimen Organizado Transnacional. En el presente trabajo nos abocaremos, fundamentalmente, a dar respuesta a la siguiente cuestión: ante la necesidad de una Corte Penal Regional de carácter permanente y jurisdicción complementaria, ¿qué alternativas normativas existen en torno a la tipificación de los delitos objeto de persecución y sanción por la Corte?

Palabras clave: Organización, corte, delitos.

\begin{abstract}
The struggle against criminal organizations is a backbone of criminal policy of the region's countries. These organizations have reached a global dimension and they have escaped control by national institutions. Faced with this phenomenon, States experience difficulties in implementing effective criminal policies. Faced with this situation, the creation of Regional Court against Organized Transnational Crimes has been raised. In this paper, we strive mainly to provide an answer to the following question: faced with the necessity of a permanent Regional Criminal Court with complementary jurisdiction, which normative alternatives exist in order to define and establish the punishment for the offences that the Court would prosecute and penalize?
\end{abstract}

Key words: organization, court, offenses.

\section{Introducción}

En el presente trabajo nos proponemos trabajar una temática que forma parte de la agenda de cooperación internacional en materia penal de los países de la región, en particular, el 
CORDINI, Nicolás. "Jurisdicción regional y delitos de organización: diversas alternativas".

desarrollo de una política criminal regional contra el crimen organizado transnacional, a partir del establecimiento de una Corte Penal Regional de carácter permanente y de jurisdicción complementaria. Ahora bien, innumerables problemáticas se desprenden de una propuesta de tal envergadura. Nosotros, a partir del presente estudio, nos abocaremos, a dar respuesta a la siguiente cuestión: asumiendo la existencia de una Corte Penal Regional contra el Crimen Organizado Transnacional de carácter permanente y jurisdicción complementaria, ¿qué alternativas normativas existen en torno a la tipificación de los delitos objeto de persecución y sanción por la Corte?

\section{Marco de institucional de la investigación y metodología seleccionada.}

El presente trabajo se enmarca en nuestro proyecto de investigación especial ${ }^{1}$, financiado por la Universidad Nacional del Litoral (Santa Fe, Argentina) denominado "Globalización y Derecho penal: el fenómeno de la criminalidad organizada. Situación en la legislación argentina y países del MERCOSUR"2. A su vez, el proyecto cuenta con un objetivo de naturaleza propositiva tendiente a desarrollar estrategias normativas regionales que posibiliten un mejor abordaje del fenómeno en cuestión. El objetivo del presente trabajo consiste en presentar, en términos generales, las estrategias de construcción normativa que, según nuestra perspectiva de análisis, resultan necesarias para abordar el fenómeno objeto de estudio.

La metodología seleccionada a los efectos de realizar el presente trabajo de investigación se basa en herramientas que se corresponden con una estrategia metodológica cualitativa. Se identifican como unidades informantes las siguientes: (i) legislación penal de los Estados partes del MERCOSUR y países asociados, en la que se recepte el elemento "organización"; demás legislación internacional en la materia: Convención de Naciones Unidas contra la Corrupción de 2003, Convención de Naciones Unidas contra la Delincuencia Organizada Transnacional y sus Protocolos, Estatuto de Roma de la Corte Penal Internacional de 2000, Convención de Naciones Unidas Contra el Tráfico Ilícito de Estupefacientes y Sustancias Psicotrópicas de 1988, Convención de la UNESCO sobre las Medidas que Deben Adoptarse para Prohibir e Impedir la Importación, Exportación y la Transferencia de Propiedad Ilícita de Bienes Culturales de 1970, Legislación regional en la materia: Convención Interamericana contra la Corrupción de 1996, Convención Americana Sobre Derechos Humanos, Tratados, Protocolos y Acuerdos del MERCOSUR, etc.); (ii) Doctrina jurídica: revistas jurídicas especializadas en la temática penal tanto

\footnotetext{
${ }^{1}$ La Universidad Nacional del Litoral organiza su arquitectura institucional en materia de investigación en torno a los CAI+D (Curso de Acción para la Investigación y el Desarrollo). La mencionada política consiste básicamente en agrupar por líneas de investigación a los Proyectos de I+D (PI) en Programas de Actividades Científicas y Tecnológicas (PACT), como un modo de facilitar el logro de objetivos concurrentes de dichos proyectos y de hacer más eficientes la adquisición de equipamiento, bibliografía, etc., de uso compartido. También están previstos los denominados PI especiales que por estar orientados a la producción de conocimiento en áreas caracterizadas por la ausencia de líneas de investigación en la temática, no son agrupados en un PACT.

${ }^{2}$ Aprobado mediante resolución del Consejo Superior de la UNL No 205/13. El mencionado proyecto tiene como objetivo la realización de un estudio comparativo de la normativa vigente en materia de "delitos de organización" entre los países miembros del MERCOSUR y Estados asociados teniendo en cuenta de qué manera dicha nueva categoría permea la configuración del ilícito generando enormes implicancias en relación a los principios y garantías constitucionales.
} 
Polít. crim. Vol. 12, № 23 (Julio 2017), Art. 2, pp. 56-77.

[http://www.politicacriminal.cl/Vol_12/n_23/Vol12N23A2.pdf]

nacionales como extranjeras, obras bibliográficas versadas sobre la temática de los delitos de organización y sobre jurisdicción internacional en materia penal. Respecto de las técnicas de investigación, recurrimos al análisis documental: análisis de contenido. Para ello se conformaron una serie de instrumentos (fichas de análisis) adecuados para cada tipo de documento. Ello posibilitó la sistematización de datos, facilitando su correlación y su posterior procesamiento, a fin de constituir una muestra representativa sobre unidades informantes.

\section{El Derecho Penal Internacional: su status disciplinario.}

A la hora de desarrollar una política criminal que opere más allá de los límites de un Estado nación, basada no solamente en la cooperación en materia criminal sino, yendo más allá, a partir del establecimiento de un Tribunal Internacional de carácter permanente que juzgue a personas y no a Estados surge, insoslayablemente, la cuestión acerca de la existencia de un Derecho penal diverso al que opera, como expresión máxima del poder soberano, al interior de cada Estado. La idea de un Derecho penal internacional como disciplina autónoma todavía sigue siendo resistida especialmente por el campo jurídico-penal ${ }^{3}{ }^{4}$. Dicha reticencia se basa en que esta rama del Derecho representa la máxima expresión del ejercicio soberano del Estado, que este último ejerce con exclusividad. La constitución del Derecho penal como disciplina científica viene de la mano de formación del Estado moderno, a través de la imposición de límites al príncipe o soberano a la hora de perseguir y castigar los crímenes (ius puniendi). Dicho en otros términos, el ejercicio de la facultad de castigar, constituye la máxima expresión del ejercicio de la soberanía.

La idea de un Derecho penal de naturaleza internacional nació como consecuencia de los crímenes de masas cometidos durante el siglo XX. A partir de la persecución y sanción de

\footnotetext{
${ }^{3}$ Cuando utilizamos el término "disciplina" seguimos el concepto establecido por Wallerstein que refiere, en realidad, a tres cosas al mismo tiempo. "En primer lugar, a categorías intelectuales, modos de afirmar que existe un campo de estudio definido con algo parecido a límites, aunque sean controvertidos o borrosos, y con modalidades de investigación separadas como legítimas. En este sentido, las disciplinas son constructos sociales (...) En segundo lugar, las disciplinas son estructuras institucionales que han ido adaptando una forma cada vez más elaborada desde el siglo XIX. Las universidades se dividen en departamentos que llevan nombres disciplinares, los títulos universitarios corresponden a disciplinas específicas y los profesores tienen cargos que también comprenden el nombre de la disciplina a la que se dedican (...) Por último, las disciplinas son también una cultura. Habitualmente, los académicos que dicen pertenecer a un grupo disciplinar comparten con los otros miembros del grupo experiencias y contactos: han leído los mismos textos 'clásicos'; participan de los mismos debates tradicionales, que a menudo son distintos de los de las disciplinas lindantes; tienen un mismo estilo y reciben recompensas por ello". WALLERSTEIN, Immanuel, Las incertidumbres del saber, BARBA, Julieta; JAWERBAUM, Silvia (Trads.), Barcelona: Gedisa, 2005, pp. 141-142.

4 Cuando hablamos de "campo" hacemos referencia a la categoría "campo científico" desarrollada por Bourdieu, quien lo define de la siguiente manera: "El campo científico como sistema de relaciones objetivas entre las posiciones adquiridas (por las luchas anteriores) es el lugar (es decir, el espacio de juego) de una lucha de competencia que tiene por desafío específico el monopolio de la autoridad científica, inseparablemente definido como la capacidad técnica y como el poder social, o si se prefiere, el monopolio de la competencia científica, entendida en el sentido de la capacidad de hablar y actuar legítimamente (es decir, de manera autorizada y con autoridad) en materia de ciencia, que es socialmente reconocida a un agente determinado". BOURDIEU, Pierre, "La spécificité du champ scientifique et les conditions sociales du progrès de la raison", Sociologie et sociétés, Vol. 7, no 1 (1975), pp. 91-118, pp. 91-92. Las traducciones del inglés, del alemán y del francés al español son de nuestra autoría salvo que se indique lo contrario.
} 
CORDINI, Nicolás. "Jurisdicción regional y delitos de organización: diversas alternativas".

tales delitos mediante la constitución de tribunales ad hoc y ex post facto ${ }^{5}$, se fue originando un conjunto de reglas que podríamos denominar "Derecho penal internacional"6. Tales reglas no están, sin embargo, exentas de críticas puesto que violan principios básicos del Derecho penal tales como el de legalidad o la garantía del juez natural ${ }^{7}$. Según Ambos "el carácter esencialmente retroactivo de este tipo de jurisdicción" es "el defecto congénito de los tribunales $a d$ hoc". Tornándose en soluciones políticas de los vencedores sobre los vencidos en flagrante violación a las garantías básicas que otorga el Derecho penal.

Dichas irregularidades han sido salvadas a partir del Estatuto de Roma que crea la Corte Penal Internacional ("CPI") ${ }^{9}$, siendo el primer instrumento de tutela jurisdiccional internacional de naturaleza penal, permanente e independiente, facultado para investigar, perseguir y sancionar, de manera complementaria a los Estados miembros, a los presuntos autores de determinados delitos a saber, aquellos que son considerados como los más graves por la Comunidad Internacional en su conjunto: genocidio, crímenes de lesa humanidad, crímenes de guerra y crimen de agresión. A partir de la conformación de la CPI

${ }^{5}$ El Tribunal Militar Internacional de Núremberg (1945); el Tribunal Militar Internacional de Tokio (1946); el Tribunal Penal Internacional para la Ex-Yugoslavia, con sede en la Haya (1993), el Tribunal Militar Internacional para los crímenes cometidos en Ruanda (1994), en Arusha y el Tribunal para el Genocidio Camboyano (2006).

${ }^{6}$ Siguiendo a Triffterer: "derecho penal internacional en sentido formal es el conjunto de todas las normas de naturaleza penal del derecho internacional, que conectan a una conducta determinada —crímenes internacionales - ciertas consecuencias típicamente reservadas al derecho penal y que, como tales, son aplicables directamente". TRIFFTERER, Otto, Dogmatische Untersuchungen zur Entwicklung des materiellen Völkerstrafrechts seit Nürnberg, Freiburg i.Br.: Albert, 1966, p. 34. Para Kai Ambos se trata de una combinación de principios de Derecho penal y de Derecho internacional. Del primero toma las ideas de responsabilidad individual y de reprochabilidad de una determinada conducta, del segundo, en cambio, toma las figuras penales, sometiendo a la conducta en cuestión a una punibilidad autónoma de Derecho internacional (principio de responsabilidad penal directa del individuo según el derecho internacional). AMBOS, Kai, "La construcción de una parte general del derecho penal internacional", Revista penal, vol. 17 (2006), pp. 5-33, p. 5.

${ }^{7}$ Un ejemplo claro de violación fue el Tribunal Militar Internacional de Núremberg que no garantizó (prohibiéndolo expresamente) el derecho de recusación que goza todo sujeto sometido a proceso.

${ }^{8}$ Y añade: "La creación ex post facto de los tribunales ad hoc infringe ante todo el elemento temporal del principio nullum crimen, es decir, la prohibición de la retroactividad de las leyes penales. Todos los tribunales ad hoc -desde Núremberg a La Haya, Arusha, Freetown, Pnom Penh, Bagdad y El Líbano (este último situado en La Haya) - fueron establecidos con posterioridad a la comisión de los crímenes que ellos mismos iban a juzgar". AMBOS, Kai, "El derecho penal internacional en la encrucijada: de la imposición ad hoc a un sistema universal basado en un tratado internacional”, Política Criminal, vol. 5, n 9 (2010), pp. 237-256, p. 238, en http://www.politicacriminal.cl/Vol 05/n 09/Vol5N9A6.pdf [visitado el 12.09.2016]. También Kelsen reconoce que el Tribunal de Núremberg aplicó normas ex post facto, pero le resta importancia a dicho principio en el derecho internacional. Así "Hay poca duda que el Acuerdo de Londres provee una pena individual a actos que al momento en que fueron realizados no eran punibles ni por el derecho internacional ni por el nacional. La regla contra la legislación retroactiva ciertamente no ha sido respetada por el Acuerdo de Londres. Sin embargo esta regla no es para nada válida en el derecho internacional, y es sólo es válida en el derecho nacional con importantes excepciones. Luego añade que La norma "es solo retroactiva en tanto ella estableció responsabilidad criminal individual por actos que al momento en que fueron cometidos constituían violaciones al derecho internacional vigente pero para el cual el derecho sólo proveía responsabilidad colectiva". KELSEN, Hans, "Will the Judgment in the Nuremberg Trial Constitute a Precedent in International Law?”, The International Law Quarterly, Vol. 1 n 2 (1947), pp. 153-171, pp. 164-165.

${ }^{9}$ Ambos habla de un principio de "tabula rasa", borrón y cuenta nueva respecto de la normativa los tribunales ad hoc. AMBOS, El derecho penal internacional en la encrucijada, cit. nota no 8, pp. 241 y ss. 
Polít. crim. Vol. 12, № 23 (Julio 2017), Art. 2, pp. 56-77.

[http://www.politicacriminal.cl/Vol_12/n_23/Vol12N23A2.pdf]

podemos hablar de un Derecho penal internacional basado en los principios de legalidad, personalidad de la pena, ne bis in idem, jurisdicción complementaria, entre otros ${ }^{10}$.

Esta nueva disciplina, que combina potestad punitiva con la dimensión internacional, parte de la premisa de un Derecho penal no basado en la idea de soberanía estatal, es decir un Derecho penal que ejerce el ius puniendi sin soberano. Dicha solución se hace posible a partir del desarrollo de un concepto de ciudadanía global basado en la protección de los derechos humanos fundamentales garantizados por múltiples tratados, tanto de escala universal como regional ${ }^{11}$.

\section{Derecho Penal Regional: la problemática del crimen organizado transnacional y la jurisdicción internacional como vía de solución.}

A nivel regional los gobiernos se encuentran en la necesidad de dar una solución eficaz a uno de los mayores flagelos delictivos que socaba las bases de la seguridad de los Estados. No se trata de crímenes de lesa humanidad, competencia de la CPI, sino del crimen organizado; siendo sus consecuencias lesivas igualmente significativas. Las organizaciones criminales asociadas al tráfico de estupefacientes, la trata de personas, el tráfico de armas, el lavado de activos, y otros crímenes de naturaleza transnacional, constituyen un problema central de la política criminal de los países de la región. Dichas organizaciones han alcanzado una dimensión regional y han escapado del control de las instituciones nacionales. Siguiendo a Silva Sánchez,

“...los fenómenos económicos de la globalización y de la integración económica dan lugar a la conformación de modalidades nuevas de delitos clásicos, así como a la aparición de nuevas formas delictivas. Así, la integración genera una delincuencia contra los intereses financieros de la comunidad producto de la integración (fraude al presupuesto — criminalidad arancelaria-, fraude de subvenciones), al mismo tiempo que contempla la corrupción de funcionarios de las instituciones de la integración. Por lo demás, genera la aparición de una nueva concepción de lo delictivo, centrada en elementos tradicionalmente ajenos a la idea de delincuencia como fenómeno marginal; en particular, los elementos de organización, transnacionalidad y poder económico." ${ }^{2}$.

\footnotetext{
${ }^{10}$ Muñoz Conde ve en la Corte penal internacional como la única posibilidad de que el Derecho penal internacional no se convierta en un "Derecho penal del enemigo" y, lo que es aún peor, en un Derecho penal del "enemigo vencido", dejando en la impunidad a los poderosos vencedores. MUÑOZ CONDE, Francisco, “Es el Derecho penal internacional un 'Derecho penal del enemigo’?”, Revista Penal, vol. 21 (2008), pp. 93102 , p. 100 ,

en: http://rabida.uhu.es/dspace/bitstream/handle/10272/12023/Es\%20el\%20Derecho.pdf?sequence=2 [visitado el 12.09.2016].

${ }^{11}$ En igual sentido Ambos afirma: "un poder punitivo trasnacional se puede fundar sin duda alguna con referencia en los derechos humanos interculturalmente reconocidos. Una fundamentación semejante presupone, desde luego, una concepción del derecho penal que parta del individuo y de su dignidad humana inviolable, absolutamente en el sentido de la relación de reconocimiento libre, igual y mutua de Kant, basada en esa dignidad humana". AMBOS, Kai, "La construcción de una parte general del derecho penal internacional" en: VV.AA., Temas actuales de derecho penal internacional. Contribuciones de América Latina, Alemania y España, Montevideo: Konrad-Adenauer-Stiftung Verlag, 2005, pp. 13-40. p. 21.

${ }^{12}$ SILVA SÁNCHEZ, Jesús-María, La expansión del Derecho penal. Aspectos de la política criminal de las sociedades postindustriales, Madrid: Civitas, 1999, pp. 85-86. Según Vogel "La internacionalización del Derecho penal y del proceso penal es una forma de aparición de la interlegalidad. Los sistemas jurídicos inter
} 
CORDINI, Nicolás. "Jurisdicción regional y delitos de organización: diversas alternativas".

Frente a este fenómeno los Estados nación se encuentran en una situación de dificultad cuando no de imposibilidad- de desplegar una política criminal adecuada en términos de efectividad. El hecho de que las organizaciones criminales desplieguen su accionar allende las fronteras estatales -ámbito dentro del cual el Estado puede desplegar su facultad de imperio- sumado a los escasos recursos con que cuentan los Estados para desarrollar las mencionadas políticas, y a la connivencia que encuentran dichas organizaciones con actores que operan en los diversos niveles de intervención en la prevención y sanción del delito (control de fronteras, cuerpo de policía, sistema judicial, sistema penitenciario, etc.) trae como consecuencia que la política criminal que se adopte al efecto sea de naturaleza simbólica.

\subsection{La Corte Penal Regional: una posible solución.}

Ante la situación descrita, desde diversos sectores tales como la academia, el sector gubernamental nacional y regional (v.gr. Unasur, Parlasur), organizaciones no gubernamentales, entre otros, han planteado la necesidad de crear una Corte Penal Regional contra el Crimen Organizado Transnacional (en adelante la Corte). Los diversos antreproyectos difieren en torno al alcance regional que debe tener la Corte (¿Mercosur? ¿Sudamérica?, ¿Latinoamérica y el Caribe?, etc.), como así también en torno a los posibles delitos objeto de persecución y sanción por parte de la Corte (especialmente en delitos de mediana o escasa gravedad tales como el cibercrimen). Todos ellos concuerdan, no obstante, en que la Corte debe ser un tribunal permanente con competencia penal destinado a la persecución y sanción de individuos y no de Estados y debe basarse, al igual que la CPI, en el principio de jurisdicción complementaria.

\subsection{Antecedentes a favor de la constitución de una jurisdicción penal regional.}

La conformación de una Corte Regional contra el Crimen Organizado Transnacional cuenta con una serie de antecedentes que la sustentan. Diversos factores juegan a favor de su constitución; a mero título ejemplificativo, mencionamos los siguientes:

(i) El antecedente de la Corte Penal Internacional (CPI). Todos los Estados objeto de Estudio han suscripto el Estatuto de Roma y, en consecuencia, han reconocido la jurisdicción de la CPI en dicha materia. Bien es verdad, que aquí no juega el argumento " $a$ fortiori" y, de hecho, los Estados podrían no tener interés en dejar en manos de otra jurisdicción la persecución y sanción de delitos comunes. Sin embargo, los Estados estudiados han reconocido la jurisdicción complementaria de la CPI y ello, por sí sólo, constituye un argumento potente a la hora de crear otro tribunal con similares características.

y supranacionales influyen en los ordenamientos jurídico penales nacionales y provocan su resistencia (...) El hecho de que la criminalidad actúe, a causa de la globalización, de forma cada vez más transnacional, como en el caso del terrorismo internacional, la criminalidad organizada internacional o el tráfico ilegal de drogas o de personas, hace de motor de la internacionalización". VOGEL, Joachim, "La internacionalización del Derecho penal y del Proceso penal", Revista penal, vol. 22 (2008), pp. 160-167, p. 161, en: http://www.uhu.es/revistapenal/index.php/penal/article/view/367/358 [visitado el 12.09.2016]. 
Polít. crim. Vol. 12, № 23 (Julio 2017), Art. 2, pp. 56-77.

[http://www.politicacriminal.cl/Vol_12/n_23/Vol12N23A2.pdf]

(ii) El antecedente de la Convención de las Naciones Unidas contra la Delincuencia Organizada Transnacional y sus Protocolos. Al igual que el Estatuto de Roma, ha sido ratificado por todos los Estados objeto de estudio. Esta Convención -adoptada por la Resolución 55/25 de la Asamblea General de Naciones Unidas del año 2000- establece el marco general de lo que debe entenderse por delincuencia organizada transnacional, a la vez que prevé medidas, a adoptar por los Estados partes, tendientes a prevenir, reprimir y sancionar los delitos definidos por la Convención y sus Protocolos. Si bien no tiene como finalidad establecer una jurisdicción internacional en la materia, esta normativa establece, no obstante, múltiples medidas de cooperación judicial, que sirven de sustento a una posible Corte Regional.

(iii) La existencia del bloque regional MERCOSUR y los acuerdos de cooperación en la materia objeto de análisis: Dentro de la estructura del bloque regional "MERCOSUR" existen múltiples acuerdos celebrados entre los Estados partes y otros Estados asociados, cuyo objetivo es la cooperación internacional en materia penal. A modo de ejemplo, citamos: 1) Acuerdo de Asistencia Jurídica Mutua en Asuntos Penales entre los Estados Partes del MERCOSUR, la República de Bolivia y la República de Chile (Buenos Aires, 18 de Febrero de 2002); 2) Acuerdo contra el Tráfico Ilícito de Migrantes entre los Estados Partes del MERCOSUR (Belo Horizonte, 16 de diciembre de 2004); 3) Acuerdo contra el Tráfico Ilícito de Migrantes entre los Estados Partes del MERCOSUR, la República de Bolivia y la República de Chile (Belo Horizonte, 16 de diciembre de 2004). La importancia de estos Acuerdos yace en que tienen como objeto la cooperación jurídica entre Estados, a la vez que se comprometen a perseguir y sancionar delitos, característicos de la delincuencia organizada internacional.

(iv) La existencia de sistemas penales similares. El mencionado antecedente es de suma importancia, dado que el hecho que los Estados objeto de estudio compartan en materia penal (tanto en lo que respecta al Derecho sustantivo como al Derecho procesal) sistemas similares, facilita el establecimiento de una jurisdicción regional. Todos los países siguen la tradición jurídica continental europea y, en la dogmática jurídico-penal, la denominada teoría del delito ${ }^{13}$. Existe, asimismo, una gran similitud en las teorías penales propuestas por Raúl Eugenio Zaffaroni en Argentina, Juares Estevam Xavier Tabares en Brasil, Bustos Ramírez en Chile, Gonzalo Fernández en Uruguay ${ }^{14}$, etc. A la vez, en materia procesal penal se observa una clara tendencia a la consolidación del denominado sistema acusatorio. La similitud de los sistemas penales constituye una gran ventaja de nuestra región frente a otras, como por ejemplo la Unión Europea, en la cual paso previo a acuerdos en materia penal, deben establecerse principios comunes mínimos entre los múltiples sistemas penales,

\footnotetext{
${ }^{13}$ BACIGALUPO, Enrique, Derecho Penal. Parte general, $2^{a}$ edición, Buenos Aires: Hammurabi, 1999 , p. 197. MURMANN, Uwe, Grundkurs Strafrecht. Allgemeiner Teil, Tötungsdelikte, Körperverletzungsdelikte, $2^{a}$ edición, München: C.H. Beck., 2013, pp. 50 y ss.

${ }^{14}$ Véase, ZAFFARONI, Raúl, et al., Derecho penal: Parte General, $2^{a}$ edición, Buenos Aires: Ediar 2003; TAVARES, Juarez Estebam Xavier, Teoría del injusto penal, Buenos Aires: B de F, 2010; BUSTOS RAMÍREZ, Juan, HORMAZABAL MALARÉE, Hernán, Lecciones de Derecho Penal. Parte general, Madrid: Trota, 2006; FERNÁNDEZ, Gonzalo, Bien jurídico y sistema del delito, B de F, Buenos Aires, 2004.
} 
CORDINI, Nicolás. "Jurisdicción regional y delitos de organización: diversas alternativas".

lo que genera reticencias, por parte de los Estados, a dichos acuerdos, puesto que conllevan la necesidad de flexibilizar determinados postulados básicos de sus respectivos sistemas ${ }^{15}$.

\subsection{Jurisdicción complementaria, no supranacionalidad.}

La constitución de una Corte como política criminal regional contra el crimen organizado transnacional estaría basada en el principio de jurisdicción complementaria tomado de la CPI. El estatuto de Roma no define en ningún lado el concepto "complementariedad", sino sólo enuncia las causales que habilitan su ejercicio en los artículos 17 a 20. No obstante, del párrafo 10 del preámbulo y del artículo $1^{\circ}$ se concluye que ella está destinada a suplantar la jurisdicción interna ante violaciones internacionales ${ }^{16}{ }_{-}^{17}$, en vez de suplantar la aplicación doméstica de normas internacionales. El principio de complementariedad está destinado a conservar el poder de la CPI sobre Estados irresponsables que se niegan a someter a proceso a quienes han cometido crímenes internacionales atroces, o se encuentran en una imposibilidad de hacerlo. Este principio equilibra ese poder supranacional que posee la CPI contra el derecho soberano del Estado a perseguir a sus propios nacionales sin interferencia externa $^{18}$.

El principio antes descrito, sería la piedra angular de la relación entre la Corte Regional y las jurisdicciones nacionales para la implementación de las obligaciones contraídas por los Estados relativas a la investigación y enjuiciamiento de los autores de los delitos objeto de la Convención que la cree. De este modo, el principio de complementariedad tendría una naturaleza mixta: por un lado, daría prelación a las jurisdicciones nacionales para investigar y juzgar (o en su caso, extraditar) a los responsables de los delitos en cuestión y por otro lado, garantizaría que, cuando los Estados no quieran o no puedan ejercer sus funciones jurisdiccionales, operase la Corte en reemplazo. De ninguna manera se constituiría en un tribunal supranacional, revisor de las decisiones internas pues, en la medida que los Estado asumieran su jurisdicción para investigar y sancionar el delito, la Corte carecería de competencia alguna.

\footnotetext{
${ }^{15}$ En torno a la constitución de un Derecho penal federal en el bloque europeo, que dé respuestas a problemas tales como el de la criminalidad transnacional la dogmática jurídico-penal de raíz alemana necesariamente debe convivir con la tradición jurídica del Common Law. SILVA SÁNCHEZ, La expansión, cit. nota ${ }^{\circ}$ 12, p. 85. Acerca de la armonización del Derecho penal en la Unión Europea véase: VOGEL, Joachim, "Estado y tendencia de la armonización del Derecho penal material en la Unión europea", Revista penal, vol. 10 (2002), pp. 112-129, en: http://www.uhu.es/revistapenal/index.php/penal/article/view/147/142 [visitado el 12.09.2016].

16 “...la Corte Penal Internacional establecida en virtud del presente Estatuto será complementaria de las jurisdicciones penales nacionales" (Estatuto de Roma de la Corte Penal Internacional).

17 "Artículo $1^{\circ}$ : ...La Corte será una institución permanente, estará facultada para ejercer su jurisdicción sobre personas respecto de los crímenes más graves de trascendencia internacional de conformidad con el presente Estatuto y tendrá carácter complementario de las jurisdicciones penales nacionales..." (Estatuto de Roma de la CPI).

${ }^{18}$ EL ZEIDY, Mohamed H., The Principle of Complementarity in International Criminal Law: Origin, Development and Practice, Boston: Nihjoff Publishers, 2008, pp. 157-158.
} 
Polít. crim. Vol. 12, № 23 (Julio 2017), Art. 2, pp. 56-77.

[http://www.politicacriminal.cl/Vol_12/n_23/Vol12N23A2.pdf]

\section{Una aproximación al concepto “organización”: el problema de la doble vía.}

El mayor problema que presenta una política como la que se propone llevar a cabo es la de determinar su objeto, puesto que, al interior de la dogmática jurídico-penal, no existe consenso respecto de lo que se entiende por "crimen organizado". Como veremos a continuación, el mencionado concepto admite diversas connotaciones, es por ello que en el presente trabajo nos abocaremos tanto a determinar el concepto en cuestión, como así también a describir las diversas vías de punición que la Corte podría adoptar.

Al investigar en materia de "crimen organizado", no contamos con un concepto, en tanto objeto de estudio, como punto de inicio ${ }^{19}$. Por el contrario, el verdadero propósito del estudio sobre el "crimen organizado" o, para ser más preciso, utilizando el léxico jurídicopenal, "delitos de organización", es determinar en qué consiste el mencionado fenómeno. Una definición de "delito de organización" es, por lo tanto, un posible resultado antes que una condición previa del estudio sobre la criminalidad organizada ${ }^{20}$.

La existencia de delitos cometidos a través de organizaciones no es un fenómeno que conlleve ninguna novedad para la disciplina penal puesto que, desde la aparición de los delitos de pertenencia a una asociación criminal, la dogmática jurídico-penal se ha visto en la necesidad de fundamentar su punición -o bien su inconstitucionalidad-, como así también ha tenido que desplegar argumentos que sirvan para diferenciar esta modalidad delictiva de la concurrencia de personas en el delito (participación). Lo que resulta extraño al buen y viejo Derecho penal liberal es la expansión de la categoría "organización" dentro de las legislaciones penales. Esta reorientación político-criminal se manifiesta a través de diversas variantes. Dichas manifestaciones no surgieron al unísono sino, por el contrario,

${ }^{19}$ LAMPE, Klaus von, "The study of organised crime: An assessment of the state of affairs" en: INGVALDSEN, Karsten; LUNDGREN SORLI, Vanja (Eds.), Organised Crime: Norms, markets, regulation and research, Oslo: Unipub, 2009, p. 165-211. p. 166.

${ }^{20}$ KELLY, Robert J., "Criminal Underworlds: Looking Down on Society of Bellow" en: KELLY, Robert J., (Ed.), Organized crime: Cross-Cultural studies, New Jersey: Rowman \& Littlefield, 1986, p. 10. Lampe señala tres grandes problemas a la hora de conceptualizar el crimen organizado. En primer lugar, resulta difícil delinear la criminalidad organizada como un objeto de estudio; pues ésta no es ni un claro fenómeno empírico discernible, ni encontramos acuerdo sobre cuál debe ser su "esencia" o "naturaleza". Más bien, una amplia variedad de personas, estructuras y eventos están, en variado grado y combinación, subsumidos en este concepto. Debido a este carácter esquivo, la frase "crimen organizado" puede asumir una experiencia de sí misma bastante independiente de la realidad social a la que se supone que debe estar relacionada. Es por ello que los investigadores en la materia no sólo se enfrentan al desafío de establecer un concepto unívoco, sino que también tienen que lidiar con la dualidad del crimen organizado como una faceta de la realidad social y como una construcción social. La segunda dificultad está relacionada con la falta de una terminología precisa. Así por ejemplo, conceptos básicos como los de "crimen organizado" y "redes criminales" son usados a veces indistintamente y en otras oportunidades son tratados como categorías analíticas diversas, creando, en consecuencia, mayores confusiones. El tercer problema surge cuando las visiones comúnmente sostenidas sobre la realidad del crimen organizado están en contradicción con las investigaciones científicas. Bastante a menudo lo que es considerado por los medios masivos de comunicación, por los políticos o por los agentes aplicadores de normas como un hecho establecido (organización criminal), bajo un examen más próximo resulta ser un concepto erróneo; por lo tanto, los investigadores, no infrecuentemente, están en desacuerdo con estos formadores de opinión. LAMPE, Klaus von, "Organised Crime Research in Perspective", en: DUYNE, Petrus van; LAMPE, Klaus von; PASSAS, Nikos (Eds.), Upperworld and Underworld in CrossBorder Crime, Nijmegen: Wolf Legal Publishers, 2002, pp. 189-198, p. 191. 
CORDINI, Nicolás. "Jurisdicción regional y delitos de organización: diversas alternativas".

han ido apareciendo en diversas oleadas y a través diferentes vectores que hoy pueden ser comprendidos bajo el concepto "expansión del Derecho penal"21.

El crimen organizado se caracteriza por ser un tipo de delincuencia que, por lo general, se presenta bajo la forma de una estructura organizada de poder, de cierta permanencia o continuidad temporal, integrada en un sistema vertical que le posibilita alcanzar cierto nivel de coordinación central en sus actividades ${ }^{22}$. El fenómeno de la criminalidad organizada ha sido investigado a través de diversos puntos de vista. Por un lado, a través de su evolución social. Por otro lado, a partir de su creciente tratamiento jurídico, sociológico, político y económico diferenciado, bajo nuevos puntos de vista pormenorizados, de modo que el significado que se entiende bajo el concepto "criminalidad organizada" ha variado fuertemente en el curso de la historia ${ }^{23}$. El mencionado concepto que, a nivel del Lebenswelt ${ }^{24}$, está ampliamente difundido en la actualidad, debido a su utilización por los medios de comunicación, no es tan antiguo como parece, sino que se remonta a fines del siglo pasado. Desde principio de los noventa, ha sido usado como sinónimo de "gangsterismo transnacional" en general, o de "mafia" u "organizaciones de tipo mafiosas", en particular, a partir de un proceso de internacionalización de la política americana de

\footnotetext{
${ }^{21}$ Para mayo ahondamiento véase: SILVA SÁNCHEZ, La expansión, cit. nota no 12, pp. 18-60. Diez Ripollés rechaza la postura de Silva Sánchez considerando que la denominada "expansión del derecho penal" presenta características de dos modelos diferentes, el de la sociedad del riesgo y el de la seguridad ciudadana, que abordan realidades diferentes desde perspectivas ideológicas diversas y que, por tanto, merecen un tratamiento diferenciado. El concepto de expansión deja ya de referirse primordialmente a las nuevas formas de criminalidad propias de la sociedad del riesgo, las cuales pasan a ocupar dentro de ese nuevo concepto de expansión, un lugar marginal, tanto cuantitativa como cualitativamente. En consecuencia, la identificación de la mayoría social con la víctima del delito, el descrédito de otras instancias de protección, o bien el surgimiento de nuevos gestores atípicos de la moral colectiva, entre otros, son característicos del modelo de la seguridad ciudadana y no del de la sociedad del riesgo, DIEZ RIPOLLÉS, José Luis, La política criminal en la encrucijada, Buenos Aires: B de F, 2007, p. 132; p. 156.

${ }^{22}$ Según Lampe, cinco requisitos fundamentales distinguen a la organización criminal de la multiplicidad de partícipes reunidos de modo esporádico, ellos son: 1) ingreso de recursos que posibilitan o facilitan la comisión de hechos ilícitos; 2) una ideología de justificación de las conductas criminales; 3) un status social; 4) seguridad ante la persecución penal y 5) seguridad ante otros criminales. LAMPE, Klaus von, „Was ist ,Organisierte Kriminalität'?", Aus Politik und Zeitgeschichte, Bonn: Bundeszentrale für politische Bildung, 63. Jahrgang 38-39, 2013, pp. 1-8, p. 6.

23 JÄGER, Thomas, „Transnationale Organisierte Kriminalität“, Aus Politik und Zeitgeschichte, Bonn: Bundeszentrale für politische Bildung, 63. Jahrgang 38-39, 2013, pp. 15-21, p. 15.

${ }^{24}$ Seguimos el concepto de Lebenswelt adoptado por Alfred Schütz, quien considera al mundo de la vida cotidiana "ingenua y pre-reflexivamente dado", no como algo "puesto entre paréntesis" sino, por el contrario, como el campo que el que el científico social no puede nunca abandonar, como el "hábitat natural" del problema del Verstehen. El mundo de la vida cotidiana incluye todo aquello que es dado por sabido y que normalmente no requiere reflexión, es una actitud de sentido común. BAUMAN, Zygmunt, La hermenéutica y las ciencias sociales, Buenos Aires: Nueva Visión, 2007, p. 168). Para Schütz: "Todas las explicaciones científicas del mundo social pueden, y para ciertos fines, deben referirse al sentido subjetivo de las acciones de seres humanos en los que se origina la realidad social" SCHÜTZ, Alfred, El problema de la realidad social: Escritos I, Buenos Aires: Amorrortu, 1974, p. 73. El Lebenswelt se constituye de este modo en el escenario y el objeto de nuestras acciones e interpretaciones. SCHÜTZ, Alfred, On Phenomenology and Social Relations, Chicago: Chicago University Press, 1973, p. 73. El mundo de la vida cotidiana es también, desde el principio, un mundo social cultural dentro del cual las personas se relacionan, en múltiples formas de interacción, con semejantes a quienes conocen en grados diversos de intimidad y anonimia. Y Sólo en él se puede constituir un entorno comunicativo común (gemeinsame kommunikative Umwelt). SCHÜTZ, Alfred; LUCKMANN, Thomas, Strukturen der Lebenswelt, Konstanz: Verlag C.H. Beck, 2003, p. 29.
} 
Polít. crim. Vol. 12, № 23 (Julio 2017), Art. 2, pp. 56-77.

[http://www.politicacriminal.cl/Vol_12/n_23/Vol12N23A2.pdf]

combate contra el narcotráfico. En este sentido, la "organización criminal transnacional" se ha convertido en un concepto que es parte integral del vocabulario de los agentes encargados del diseño de la política criminal alrededor del globo ${ }^{25}$. Muchos gobiernos están en un continuo proceso de diseño de nuevas vías para combatir aquello que, para muchos, constituye un nuevo problema descubierto. Tratados bilaterales y multilaterales, Convenciones surgidas en el seno de Naciones Unidas, instituciones encargadas de hacer cumplir la normativa internacional dictada al efecto y agencias de inteligencia abocadas a investigar las actividades de organizaciones tales como "La Camorra", "Cosa Nostra", "Yakusa" o, a nivel regional de cárteles tales como el de Medellín o el de Sinaloa, son manifestaciones de esta nueva problemática.

La aparición de la categoría "organización" se visualiza, al interior de las legislaciones penales, a través de tres diversas variantes, ellas son: a) la tipificación de delitos característicos de esta forma de criminalidad (p. ej. el delito de trata de personas, lavado de activos, tráfico de armas, etc.); b) la introducción del elemento "organización" como agravante de una serie de delitos más o menos tradicionales (por ejemplo el caso del delito de robo calificado cuando es cometido en asociación o banda) ${ }^{26}$; y por último, 3) los clásicos delitos de pertenencia a una organización (v.gr. el delito de asociación ilícita o asociación para delinquir) ${ }^{27}$. En resumen, las organizaciones criminales aparecen en la

${ }^{25}$ En los Estados Unidos de América, donde ya en la primera mitad del siglo xx se habían construido dependencias de la Cosa Nostra italiana, el campo problemático de la criminalidad organizada es discutido intensamente desde hace décadas. La Conferencia de la ONU contra la criminalidad transnacional se basó en los intentos americanos por definir a la organización criminal. Klaus C. Rohr, agregado diplomático de la embajada americana en Alemania, explicó los esfuerzos americanos para una definición de la criminalidad organizada de la siguiente manera: "El departamento de justicia y el FBI definen a la organización criminal como una continua y auto-sostenible asociación criminal, que obtiene su posición de poder a través de la corrupción y la intimidación y que está motivada por el ánimo de lucro". Luego de esta definición, la organización criminal es una unión cuyo primer objetivo es la conservación del poder. Este poder sólo puede ser alcanzado cuando actúa en secreto y todos los competidores, así como las agencias de seguridad, son eliminados. Contra los competidores se le aplica la fuerza y la intimidación y órganos del estado son corrompidos. HOFFMANN, Martin Ludwig, Monopole der Gewalt. Mafiose Macht, staatliche Souveränität und Wiederkehr normativer Theorie, Bielefeld: Transcript Verlag, 2003, pp. 83-84.

${ }^{26}$ Así el código penal argentino art. 166 inc. $2^{\circ}$ in fine establece el supuesto en que fuese cometido en despoblado y en banda o en sentido similar el art 165 del Código penal paraguayo establece la modalidad agravada cuando el autor hurtara como miembro de una banda que se ha formado para la realización continuada de robos y hurtos. Respecto a la norma penal argentina, Boumpadre entiende que "banda" es sinónimo de asociación ilícita. Véase BUOMPADRE, Jorge, Derecho penal: parte especial, T. II; VIERA, Mario A. (Ed.), Buenos Aires: Editorial Astrea, 2001, p. 74. En igual sentido se expresa Donna, equiparando banda y asociación ilícita. DONNA, Edgardo, Derecho penal: parte especial, Tomo II-B, Santa Fe: RubinzalCulzoni, 2002, pp. 173 y ss.

${ }^{27}$ Todos los Estados objeto de estudio punen de manera similar, el hecho de formar parte de una asociación destinada a cometer delitos. Así el artículo 210 Código Penal argentino (asociación ilícita), el delito de Associação Criminosa del artículo 288 del Código Penal brasileño; la asociación para delinquir del artículo 150 del Código penal Uruguayo; el código penal paraguayo contiene en su artículo 239 tipifica la "asociación criminal". Por su parte el código penal venezolano contiene el delito de "agavillamiento" en su artículo 286 del código penal que se constituye "Cuando dos o más personas se asocien con el fin de cometer delitos, cada una de ellas será penada, por el solo hecho de la asociación”. Además, la Ley Orgánica contra la Delincuencia Organizada y Financiamiento al Terrorismo, que fue publicada en Gaceta Oficial número 39.912 del 30 de abril de 2012 de la República Bolivariana de Venezuela establece en su artículo 37 que "Quien forme parte de un grupo de delincuencia organizada, será penado o penada por el solo hecho de la asociación”. El código penal chileno regula en los artículos 292 a 294 el delito de 'asociación ilícita'. El 
CORDINI, Nicolás. "Jurisdicción regional y delitos de organización: diversas alternativas".

legislación penal a través de dos vías diversas: i) mediante el agravamiento de la pena prevista en diversos delitos cuando el mismo se haya cometido a través de un grupo organizado (casos a y b) o bien, ii) mediante los delitos de mera pertenencia a una asociación ilícita (caso c).

\section{La Corte Penal Regional: diversas soluciones de tipificación.}

A la hora de diseñar una política criminal regional contra el crimen transnacional organizado es posible adoptar, en lo concerniente a la competencia material de la Corte al menos, dos vías, a saber: a) la punición de la organización como delito independiente o bien b) la punición de determinados delitos, propios de la modernidad tardía, en la medida que sean cometidos a través de una organización. Existe una tercera vía, consistente en la combinación de las dos anteriores. Las consecuencias prácticas varían en función de la adopción de uno u otro modelo. A continuación analizaremos cada uno de ellos.

\subsection{La punición de la organización como delito autónomo (propuesta 1).}

Esta es la tendencia adoptada por los países de la región en sus legislaciones nacionales (véase nota al pie número $27{ }^{28}$. Conforme a esta perspectiva la Corte tendría la competencia (complementaria) para perseguir y sancionar el delito consistente en formar parte de una organización delictiva transnacional. Los elementos "organización y "transnacionalidad" son extraídos de la Convención de Naciones Unidas contra la Delincuencia Organizada Transnacional que define como "grupo organizado" a "un grupo estructurado de tres o más personas que exista durante cierto tiempo y que actúe concertadamente con el propósito de cometer uno más delitos graves ${ }^{29}$ o delitos tipificados con arreglo a la presente Convención" (art. 2 b). Por otro lado, la misma Convención estipula que el delito tiene carácter transnacional si: "a) Se comete en más de un Estado; b) Se comete dentro de un solo Estado, pero una parte sustancial de su preparación, planificación, dirección o control se realiza en otro Estado; c) Se comete dentro de un solo Estado, pero entraña la participación de un grupo delictivo organizado que realiza actividades delictivas en más de un Estado; o d) Se comete en un solo Estado, pero tiene efectos sustanciales en otro Estado" (art. 4).

Adoptar la vía autónoma de punición supone reconocer que la organización, por su sola existencia, pone en peligro un bien jurídico, aunque el mismo no sea siempre fácil de

Código Penal peruano en su artículo 317 tipifica "agrupación ilícita". Por último Código Penal del Estado Plurinacional de Bolivia distingue tres figuras diversas: la asociación delictuosa que sanciona el mero "formar parte" (art. 132), b) la organización criminal, que se diferencia de la figura anterior por su grado de organización y su finalidad delictiva específica (art 132 bis) y c) el delito de terrorismo definido (art. 133).

${ }^{28}$ Cabe aclarar que la punición de la asociación criminal en tanto delito autónomo respecto del delito fin, convive con subtipos agravados por el hecho de haber sido cometido de manera organizada. Esta duplicidad de vías de punición genera no pocos problemas al momento de determinar cuál es la norma aplicable, puesto que la aplicación simultánea de ambas normas (la que sanciona la pertenencia a una organización criminal por un lado, y la que agrava el delito por haberse cometido a través de una asociación) conlleva a una doble valoración del elemento asociativo (como delito autónomo y como calificante) trayendo como consecuencia una violación del principio del ne bis in ídem.

${ }^{29}$ Art 2 b) Por "delito grave" se entenderá la conducta que constituya un delito punible con una privación de libertad máxima de al menos cuatro años o con una pena más grave. 
Polít. crim. Vol. 12, № 23 (Julio 2017), Art. 2, pp. 56-77.

[http://www.politicacriminal.cl/Vol_12/n_23/Vol12N23A2.pdf]

identificar. El delito aquí tratado aparece tipificado, en las legislaciones nacionales, bajo títulos tales como "delitos contra el orden público", "delitos contra la paz pública", etc. Abordado desde una dimensión internacional, habría que reconocer la existencia de una "paz pública internacional" como objeto de tutela; bien jurídico cuya finalidad sería garantizar la protección de bienes jurídicos personales (v.gr. la vida, la integridad física, la propiedad, etc.).

En el delito aquí analizado, el autor es responsable por su mera adhesión a la organización, es decir, por formar parte de la misma. Esta fundamentación, sin embargo, no resulta satisfactoria dado que, si considerásemos al delito de organización como delito por adhesión o de pertenencia, deberían desarrollarse criterios para fundamentar el traslado de la responsabilidad de la organización en una punición de los autores individuales que formaren parte de ella. Dichos criterios deberían ser idóneos para responder la siguiente pregunta: ¿bajo qué criterios el hecho de pertenecer a una organización delictiva redunda en una imputación a la persona individual ${ }^{30}$ ?

Otra vía de escape, ha sido desarrollada en la dogmática jurídico-penal alemana bajo el título de "teoría de la anticipación" (Vorverlagerungstheorie) que ha justificado la existencia de la organización en tanto delito autónomo, considerando al delito asociativo como una anticipación (acto preparatorio) del delito fin de la asociación. La fundamentación de la punición de los miembros y colaboradores de este tipo de organizaciones radicaría en su manifiesta enemistad al Derecho (offene Rechtsfeindschaft). ${ }^{31}$ No demasiado ajeno a esta fundamentación se encuentra la postura de Jakobs, quien sostiene que la legitimación de la sanción de la pertenencia a una asociación no tiene lugar a partir de la consideración como actos preparatorios de la lesión futura de bienes jurídicos, sino como hechos que, por sí mismos infringen normas de flanqueo, cuya finalidad es garantizar los presupuestos cognitivos de la vigencia de las normas principales, provocando un menoscabo de la confianza de los ciudadanos en el sistema jurídico. ${ }^{32}$

\footnotetext{
${ }^{30}$ La teoría de la imputación, en términos generales, responde a la problemática de cuándo y bajo qué condiciones se puede establecer una relación, penalmente relevante, entre una persona y un suceso de manera que a esa persona se la pueda considerar autor y reprocharle el hecho mediante la aplicación de una pena. Véase, HRUSCHKA, Joachim, Strukturen der Zurechnung, Berlin: Walter de Gruyter, 1976. El Derecho penal, producto de la modernidad, fundado en el principio de responsabilidad individual. El Derecho penal internacional desafía el principio antes mencionado. Así, el Tribunal Penal Internacional para la Ex Yugoslavia ha reconocido la figura de la "empresa criminal conjunta" (Joint Criminal Enterprise) para imputar crímenes a dirigentes, "lo que en opinión de la doctrina habría permitido a los jueces obviar los escollos de prueba que se plantean en la búsqueda de la responsabilidad individual en casos tan complejos, donde en ocasiones ni siquiera se ha podido identificar al ejecutor". GIL GIL, Alicia, "Imputación de crímenes internacionales, ¿expansión o universalización? Problemas y vías de solución” en: GIL GIL, Alicia (Dir.), MACULAN, Elena (Coord.), Intervención delictiva y derecho penal internacional. Reglas de atribución de responsabilidad en crímenes internacionales, Madrid: Dykinson, 2013, pp. 511-587, p. 511.

${ }^{31}$ RUDOLPHI, Hans-Joachim, „Verteidigerhandeln als Unterstützung einer kriminellen oder terroristischen Vereinigung i. S. der $\S 129$ a StGB“, Festschrift für H.J. Brums zum 70. Geburtstag, Köln: Heymann, 1978, p. 318. En sentido similar Kindhäuser argumenta: "el autor, en la medida que quiere ponerse en situación de cometer un hecho antijurídico, se convierte en un riesgo para la seguridad". KINDHÄUSER, Urs: Gefährdung als Straftat: rechtstheoretische Untersuchungen zur Dogmatik der abstrakten und konkreten Gefährdungsdelikte, Frankfurt am Main: Klostermann, 1989, pp. 315-338, p. 315.

32 JAKOBS, Günther, „Kriminalisierung im Vorfeld einer Rechtsgutsverletzung“, Zeitschrift für die gesamte Strafwissenschaft, Berlin: Walter de Gruyter, vol. 97 (1985), pp. 751-785, pp. 773-774.
} 
CORDINI, Nicolás. "Jurisdicción regional y delitos de organización: diversas alternativas".

La adopción de esta perspectiva tiene sus ventajas, aunque no está exenta de críticas. Teniendo en cuenta que la misión central es el diseño de una política criminal regional, a partir de la creación de una Corte Regional una propuesta plausible estaría basada en los siguientes ejes:

- La convención debería tipificar la pertenencia a una organización criminal, en cumplimiento del principio de legalidad.

- Competencia personal: aquí surge la problemática de si la Corte debería tener competencia respecto de todo aquel que formare parte del delito asociativo o debiese limitarse sólo a determinadas acciones típicas. Recurriendo a un criterio (límite) político-criminal, es posible limitar la competencia de la Corte sólo respecto de aquellos que promuevan, dirijan u organicen la asociación, cumpliendo así la finalidad de perseguir a aquellos que ocupan los más altos cargos dentro de la organización. Por otro lado, siguiendo el criterio de la CPI, la Corte Regional no sería competente respecto de los autores o partícipes que fuesen menores de 18 años en el momento de la presunta comisión del crimen.

- Competencia material: ante esta cuestión podemos formular la siguiente pregunta: ¿la Corte se abocará solamente a la persecución y sanción del delito de organización o, por el contrario, también será competente respecto de determinados delitos fin que concurran con el delito asociativo? Y en este caso ¿de qué delitos fin estamos hablando? Dado que, desde esta perspectiva, la mera existencia de la organización constituye de por sí sola un delito autónomo, independiente de los delitos fin que ella tenga como propósito y si de lo que se trata es prevenir y sancionar nuevas formas de criminalidad, resulta idóneo establecer la competencia sólo respecto de determinados delitos fin. A saber, aquellos definidos en la Convención de Palermo (trata de personas, tráfico ilícito de migrantes, tráfico de armas de fuego, sus piezas y componentes y municiones y lavado de activos), a los que se le podría sumar el tráfico ilícito de estupefacientes y sustancias psicotrópicas ${ }^{33}$, el soborno transnacional $^{34}$ y el tráfico ilícito de bienes culturales ${ }^{35}$.

Asumir la jurisdicción también respecto de los delitos fin genera no pocos inconvenientes, dado que los respectivos delitos han sido introducidos en las diversas legislaciones nacionales con no pocas variaciones, la Corte, al ejercer su jurisdicción complementaria, sancionará los delitos conexos de conformidad con lo establecido por las legislaciones internas que fuesen competentes en el hecho. A tal fin, se deberían establecer reglas para definir cuál es la ley (Derecho local) aplicable a los delitos fin. ${ }^{36}$ Otra vía de solución, quizás la más plausible, sería limitar la competencia de la Corte sólo respecto del delito asociativo y, una vez, juzgado dicho crimen, sean las jurisdicciones nacionales las que resuelvan la punición de los delitos fin.

\footnotetext{
${ }^{33}$ Conforme a la Convención de Naciones Unidas contra el Tráfico Ilícito de Estupefacientes y Sustancias Psicotrópicas (Viena 1988).

${ }^{34}$ Convención de Naciones Unidas contra la Corrupción y Convención Interamericana contra la Corrupción.

35 Convención de la UNESCO sobre las Medidas que Deben Adoptarse para Prohibir e Impedir la Importación, Exportación y la Transferencia de Propiedad Ilícita de Bienes Culturales (Paris 1970).

36 En caso de jurisdicción internacional, el principio de la ubicuidad no otorga una solución a esta problemática. Si intervienen varias legislaciones, debería seguirse el principio de la ley más favorable al imputado.
} 
Polít. crim. Vol. 12, № 23 (Julio 2017), Art. 2, pp. 56-77.

[http://www.politicacriminal.cl/Vol_12/n_23/Vol12N23A2.pdf]

Constituir a la organización criminal transnacional como el único delito objeto de la Corte tiene la ventaja respecto de otros modelos, que analizaremos a continuación, a la hora de su instrumentalización. Un modelo como el aquí presentado resulta de fácil puesta en práctica, puesto que los Estados miembros sólo tendrían que realizar mínimas reformas legislativas. Por otro lado, al ser la organización criminal transnacional un delito de pertenencia (mera actividad), se configura de manera sencilla, con la simple realización de la conducta típica (dirigir, administrar, organizar, etc.). Pero, al tratarse de un delito de peligro, el tipo en cuestión debe soportar las críticas a las que están sometidos los delitos de tal naturaleza. Además, este modelo tiene el problema de la concurrencia de tipos (delitos fin) pues, dado que los mismos no están legislados en la Convención, genera una multiplicidad de legislaciones a la hora de sancionar los hechos provocando no pocos problemas en torno al establecimiento de la ley aplicable al hecho.

\subsection{La tipificación de las nuevas formas de criminalidad: el componente organizacional (propuesta 2).}

Esta perspectiva toma como objeto de protección determinados bienes jurídicos ante nuevas modalidades delictivas propias de la modernidad tardía. Características de estas nuevas formas de delinquir son la transnacionalidad y el componente organizacional. Para este punto de vista, la organización no es un delito independiente respecto del delito fin sino que, por el contrario, la organización forma parte de la estructura del ilícito (Unrecht), aumentando el grado de peligrosidad del mismo y repercutiendo, en última instancia, en el grado de reproche (culpabilidad) que se formule contra el autor del hecho. Siguiendo a Silva Sánchez,

"una organización delictiva es un sistema penalmente antijurídico (strafrechtliches Unrechtssystem), o sea, un sistema social en el que las relaciones entre los elementos del sistema (básicamente, personas) se hallan funcionalmente organizadas para obtener fines delictivos. La organización criminal como sistema de injusto tiene una dimensión institucional -de institución antisocial- que hace de ella no sólo algo más que la suma de sus partes, sino también algo independiente",37.

Es en dicha dimensión institucional donde radica su diferencia específica respecto a las meras agrupaciones coyunturales para cometer delitos. El fundamento de la tipificación penal del componente organizacional estaría relacionado a que dichas organizaciones suponen un incremento de la peligrosidad frente a autores individuales o concertados de modo esporádico (participación) es decir, su cualidad de disponer de la multiplicación de los distintos factores de riesgo respecto de los bienes jurídicos individuales (la vida, la integridad física, la libertad, la propiedad, etc.) afectados por las infracciones cometidas a través de la organización.

La adopción de esta perspectiva comprende el diseño de una política criminal basado una Convención Internacional que no sólo cree una jurisdicción internacional a través del

\footnotetext{
37 SILVA SÁNCHEZ, Jesús-María, “La 'intervención a través de organización', ¿una forma moderna de participación en el delito?” en: SILVA SÁNCHEZ, Jesús-María, CANCIO MELIA, Manuel (Eds.), Delitos de organización, Buenos Aires: B de F, 2008, p. 95.
} 
CORDINI, Nicolás. "Jurisdicción regional y delitos de organización: diversas alternativas".

establecimiento de una Corte de carácter permanente sino que el Tratado que la cree deberá, al mismo tiempo, establecer cuáles serán los bienes jurídicos objeto de protección, definiendo y castigando las acciones que atenten contra ellos. En otros términos, en función del principio de legalidad, se deberá establecer cuáles son las conductas prohibidas y sus respectivas penas. Paso siguiente, los Estados que se sometan a la competencia de la Corte deberán armonizar sus respectivas normativas, tarea para nada sencilla. Respecto de los delitos que serían competencia de la Corte cabe mencionar, a sólo título enunciativo, la trata de personas, el tráfico ilícito de migrantes, el tráfico de armas de fuego, sus piezas y componentes y municiones y lavado de activos, el tráfico ilícito de estupefacientes y sustancias psicotrópicas, el soborno transnacional, el tráfico ilícito de bienes culturales, etc. Otro gran problema que presenta esta tesis es la dificultad de atribuir responsabilidad "a título de autor" a aquellos que ocupan los grados jerárquicos más altos dentro de la pirámide organizacional cuando, de manera no infrecuente, no intervienen en la ejecución del hecho delictivo. No está demás aclarar, que siempre que se den los presupuestos exigidos es posible aplicar las reglas de la instigación ${ }^{38}$. El problema reside, no obstante, en determinar bajo qué presupuestos pueden ser considerados autores, por los delitos cometidos por los miembros de rango inferior sin caer en la violación de principios básicos del Derecho penal como el de responsabilidad individual.

Una posible solución la aporta Claus Roxin, quien sostiene que el aparato estatal que actúa de manera criminal, tesis de la autoría en el ámbito de aparatos organizado de poder (Täterschaft im Rahmen organisatorischer Machtapparete), constituye un prototipo de criminalidad organizada. Este autor equipara el Estado criminal con organizaciones criminales que actúan fuera de organización estatal y, frecuentemente, contra el Estado. ${ }^{39}$ La tesis de la autoría mediata (mittelbare Täterschaft) a través de un instrumento que obra dentro de un aparato organizado de $\operatorname{poder}^{40}$, ya había sido desarrollada por Roxin al elaborar su difundida teoría sobre Autoría y dominio del hecho ${ }^{41}$. Este tipo de autoría se configura cuando el autor forma parte de una estructura organizada de poder y es un intermediario en la ejecución de una acción delictiva determinada. Así, por ejemplo, los soldados o funcionarios que ejecutan órdenes de un Estado que actúa ilegalmente (v.gr. a través del exterminio, la desaparición forzada de personas, etc.). El hombre que está detrás (Hintermann der) domina ${ }^{42}$, por medio del aparato, el resultado típico, sin tener en consideración la persona, que con mayor o menor grado de azar, aparece como órgano

\footnotetext{
${ }^{38}$ FREUND, Georg, Strafrecht. Allgemeiner Teil. 2. Auflage, Berlin-Heidelberg: Springer, 2009, p. 406 y ss.

39 ROXIN, Claus, „Probleme von Täterschaft und Teilnahme bei der organisierten Kriminalität“ en: SAMSON, Erich; DENCKER, Friedrich; FRISCH, Peter; FRISTER, Helmut; REI $\beta$, Wolfram (Eds.), Festschrift für Gerald Grünwald zum siebzigsten Geburtstag, Baden-Baden: Nomos Verlagsgesellschaft, 1999, pp. 549-661, p. 560.

${ }^{40}$ BACIGALUPO, Derecho Penal. Parte general, cit. nota ${ }^{\circ} 13$, p. 504.

${ }^{41}$ Véase, ROXIN, Claus, Täterschaft und Tatherrschaft. 8. Auflage, Berlin: Walter de Gruyter, 2006.

${ }^{4}$ Según Roxin, es autor mediato no sólo el más alto jefe de una organización criminal, sino todo aquel, que en el ámbito de jerarquía de la orden criminal, transmite una orden con mando independiente. Por lo tanto, también es autor, cuando por sí mismo actúa conforme a órdenes de posiciones superiores. La autoría mediata puede, por lo tanto, consistir en una larga cadena de autores mediatos. Por el contrario, aquel que realiza trabajos preparatorios para el dador de la orden, en el cual produce por ejemplo ayuda burocrática sucia (bürokratische Handlangerdienste), sólo es colaborador. ROXIN, „Probleme von Täterschaft“, cit. nota n 39 , p. 556.
} 
Polít. crim. Vol. 12, № 23 (Julio 2017), Art. 2, pp. 56-77.

[http://www.politicacriminal.cl/Vol_12/n_23/Vol12N23A2.pdf]

ejecutor ${ }^{43}$. En estos casos, la 'fungibilidad' del sujeto que comete el hecho delictivo, quien, en caso de no acatar la orden impartida, podría ser fácilmente remplazado por otro, es lo que fundamenta la autoría mediata de los miembros superiores de la organización. Cabe aclarar que la autoría (directa) de los ejecutores, dado que no actúan coaccionados o por error, no es puesta en duda. ${ }^{44}$ Por otro lado, la CPI, admite este tipo de autoría a parir del artículo 25 (3) del Estatuto de Roma. ${ }^{45}$

\subsection{Tercera alternativa: la doble vía (propuesta 3 ).}

Esta solución es el resultado de la combinación de las propuestas anteriormente desarrolladas. Por un lado, la Corte se abocaría a la punición de aquellos formasen parte de la organización (siempre limitando la competencia a quienes promuevan, dirijan u organicen la asociación), y por otro lado, perseguiría los delitos fin cometidos a través de organizaciones de estas características. Un modelo como el expuesto, corre el riesgo de violar el principio de prohibición de doble punición, a partir de la doble valoración de un hecho, en este caso la organización delictiva, como delito independiente por un lado (por el hecho de formar parte de la misma), y como elemento del tipo objetivo, por otro. Para evitar la doble valoración, una solución plausible es erigir el tipo penal de organización delictiva transnacional como un tipo subsidiario. De este modo, sólo se aplicaría dicho tipo penal (la punición de la pertenencia cualificada a la organización delictiva en cuanto tal) cuando no fuese aplicable otro tipo penal (perteneciente a un delito fin). Es decir, en primer lugar habría que examinar si al hecho en cuestión le es aplicable alguno de los tipos penales competencia de la Corte (v.gr. tráfico de estupefacientes, trata de personas, lavado de activos, etc.) cuando dichos tipos delictivos no pudiesen ser aplicables, por faltar elementos del tipo objetivo, pero se dan los componentes del delito autónomo de asociación criminal, se procedería a la aplicación de éste.

Esta solución no está exenta de críticas. Muy por el contrario, en vez de salvar las dificultades que presentan los dos modelos anteriores, no hace sino sumarlas.

\section{Conclusiones.}

La configuración de un Derecho penal internacional otorga un marco legal para la constitución de uno de naturaleza regional que dé respuestas a la problemática de la

\footnotetext{
${ }^{43}$ ROXIN, ,Probleme von Täterschaft“", cit. nota no 39, p. 550.

${ }^{44}$ ROXIN, Täterschaft, cit. nota ${ }^{\circ} 41$, pp. 341 y ss.

45 “3. De conformidad con el presente Estatuto, será penalmente responsable y podrá ser penado por la comisión de un crimen de la competencia de la Corte quien: a) Cometa ese crimen por sí solo, con otro o por conducto de otro, sea éste o no penalmente responsable". La admisión de la autoría mediata se encuentra en la frase "por conducto de otro". Para mayor profundidad véase, AMBOS, Kai, "Art. 25 Individual Criminal Responsibility", en: TRIFFTERER, Otto (Ed.), Commentary on the Rome Statute of the International Criminal Court, München: Beck, 2008, mn. 7 y ss. La teoría del dominio del hecho ha sido utilizada en CPI en el caso Prosecutor v. Jean-Pierre Bemba Gombo, ICC 01/05-01/08. Para un estudio profundo de este caso y cómo se aplicó la mencionada teoría veáse: AMBOS, Kai, "Aspectos problemáticos de la decisión de confirmación de cargos de la Corte Penal Internacional en el caso Bemba", Revista penal, vol. 25 (2010), pp. $12-21$.
} 
CORDINI, Nicolás. "Jurisdicción regional y delitos de organización: diversas alternativas".

criminalidad organizada transnacional. El hecho que los diversos Estados de la región posean sistemas penales altamente similares, abona la hipótesis planteada.

En las legislaciones locales analizadas conviven dos tipologías, por un lado la punición de la asociación delictiva en tanto delito autónomo y, por otro, en tanto elemento del tipo objetivo de determinada clase de delitos (ilícitos en los cuales el componente asociativo es un elemento agravante del tipo básico). En la práctica, esta superposición genera la necesidad de una interpretación sistemática de los tipos penales implicados, a fin de evitar caer en la una doble valoración del elemento organizacional (violando el principio ne bis in ídem), primero como delito independiente y, luego, como componente del tipo objetivo del delito fin (por ej. elemento agravante del delito de lavado de activos).

Una solución regional debería tener en cuenta los problemas que, en las legislaciones nacionales, genera el sistema de la doble vía, debiendo orientarse por la propuesta $1 \mathrm{o}$ bien, por la 2; ninguna de ellas está exenta de críticas.

La propuesta 1, si bien es más sencilla a la hora de ser instrumentada, acarrea las dudas propias de los delitos de peligro abstracto, en torno a la constitucionalidad. ${ }^{46}$ Además, esta solución corre el peligro de aumentar los márgenes de punición de la organización, en la medida que no haya una limitación precisa respecto de la naturaleza y gravedad de los delitos fin que a través de la punición de la organización se buscan prevenir; desviándose así, de la finalidad político-criminal para la cual fue concebida.

Con la propuesta 2, dado que no supone un adelantamiento de las etapas punitivas, las críticas respecto de su dudosa constitucionalidad están salvadas. Esta vía permitiría dar un tratamiento particularizado a determinados delitos, puesto que esta modalidad de tipificación toma en cuenta las circunstancias peculiares de cada hecho delictivo, lo que no puede lograrse a través de la mera punición de la organización criminal. Como bien sostiene González Rus, ello permitiría delimitar dentro de márgenes político-criminalmente razonables el ámbito de punición de la criminalidad organizada, corrigiendo los excesos que se visualizan en las legislaciones penales de los Estados objeto de estudio. Además, simplificaría de manera eficaz la determinación de las penas y acabaría con la existencia de concursos, evitando de paso las incongruencias irresolubles que existen en las escalas penales aplicables. ${ }^{47}$ Esta solución conlleva, no obstante, la dificultad para atribuir responsabilidad a los más altos rangos de la asociación, siendo ellos los principales sujetos a perseguir, la institucionalización de la teoría de la autoría mediata, ya receptada por la CPI, constituye una vía de solución a este problema. Esta solución conlleva, no obstante, mayores dificultades a la hora de su puesta en práctica, especialmente a partir de la necesidad de armonizar los diversos tipos creados por la instancia internacional con los propios de las legislaciones nacionales. Esta cuestión no es menor, puesto que el legislador,

\footnotetext{
${ }^{46}$ Zaffaroni afirma que el tipo en cuestión es de constitucionalidad dudosa por constituir una ampliación del ámbito de la prohibición que "no puede sortearse sino en violación al principio de lesividad, y sin que a su respecto quepan legitimaciones basadas en el peligro para todos los derechos y libertades que la organización democrática estatal trata de garantizar a toda la sociedad”. ZAFFARONI, Raúl, et al, Derecho penal: parte general, $2^{a}$ edición, Buenos Aires: Ediar, 2002, p. 811.

${ }_{47}$ GONZÁLEZ RUS, Juan José, "La criminalidad organizada en el código penal español. Propuestas de reforma", Anales de Derecho, vol. 30 (2012), pp. 15-41, p. 38.
} 
Polít. crim. Vol. 12, No 23 (Julio 2017), Art. 2, pp. 56-77.

[http://www.politicacriminal.cl/Vol_12/n_23/Vol12N23A2.pdf]

de manera no infrecuente, se desmarca de los estándares fijados por instrumentos internacionales, yendo más allá de las exigencias internacionales a la hora de la receptación de los respectivos tipos penales.

En cuanto a la doble vía (posición 3) no la consideramos una buena solución, dado que reproduciría los problemas que se presentan en las legislaciones de los diversos Estados, pues la convivencia de ambas vías genera superposición de tipos penales, trayendo como consecuencia la dificultad de determinar el tipo aplicable al hecho. La alternativa de constituir al tipo que puna a la organización criminal de manera autónoma en tanto delito subsidiario no soluciona todos los problemas pues, si bien resuelve en gran medida el problema concursal, aún permanece la imprecisión en torno a los límites del poder punitivo dado que esta solución aumenta los márgenes de actuación del poder penal a límites no muy precisos. 
CORDINI, Nicolás. "Jurisdicción regional y delitos de organización: diversas alternativas".

\section{RESEÑAS BIBLIOGRÁFICAS}

AMBOS, Kai, “Aspectos problemáticos de la decisión de confirmación de cargos de la Corte Penal Internacional en el caso Bemba”, Revista penal, vol. 25 (2010), pp. 1221.

"El derecho penal internacional en la encrucijada: de la imposición ad hoc a un sistema universal basado en un tratado internacional", Política Criminal, Universidad de Talca, vol. 5, núm. 9 (2010), pp. 237-256.

, “Art. 25 Individual Criminal Responsibility", en: TRIFFTERER, Otto (Ed.), Commentary on the Rome Statute of the International Criminal Court, München: Beck, 2008.

, "La construcción de una parte general del derecho penal internacional", Revista penal, vol. 17 (2006), pp. 5-33.

, "La construcción de una parte general del derecho penal internacional", en: VV.AA., Temas actuales de derecho penal internacional. Contribuciones de América Latina, Alemania y España, Montevideo: Konrad-Adenauer-Stiftung Verlag, 2005, pp. 13-40.

BACIGALUPO, Enrique, Derecho Penal. Parte general, $2^{\mathrm{a}}$ edición, Buenos Aires: Hammurabi, 1999, p. 197.

BAUMAN, Zygmunt, La hermenéutica y las ciencias sociales, Buenos Aires: Nueva Visión, 2007.

BUOMPADRE, Jorge, Derecho penal: parte especial, T. II; VIERA, Mario A. (Ed.), Buenos Aires: Editorial Astrea, 2001.

BOURDIEU, Pierre, "La spécificité du champ scientifique et les conditions sociales du progrès de la raison", Sociologie et sociétés, Paris, vol. 7, nº 1 (1975), pp. 91-118.

BUSTOS RAMÍREZ, Juan, HORMAZABAL MALARÉE, Hernán, Lecciones de Derecho Penal. Parte general, Madrid: Trota, 2006.

DIEZ RIPOLLÉS, José Luis, La política criminal en la encrucijada, Buenos Aires: B de F, 2007.

DONNA, Edgardo, Derecho penal: parte especial, Tomo II-B, Santa Fe: Rubinzal-Culzoni, 2002.

EL ZEIDY, Mohamed H., The Principle of Complementarity in International Criminal Law: Origin, Development and Practice, Boston: Nihjoff Publishers, 2008.

FREUND, Georg, Strafrecht. Allgemeiner Teil. 2. Auflage, Berlin-Heidelberg: Springer, 2009.

GIL GIL, Alicia, "Imputación de crímenes internacionales, ¿expansión o universalización? Problemas y vías de solución” en: GIL GIL, Alicia (Dir.), MACULAN, Elena (Coord.), Intervención delictiva y derecho penal internacional. Reglas de atribución de responsabilidad en crimenes internacionales, Madrid: Dykinson, 2013, pp. 511587.

GONZÁLEZ RUS, Juan José, “La criminalidad organizada en el código penal español. Propuestas de reforma", Anales de Derecho, vol. 30 (2012), pp. 15-41.

HOFFMANN, Martin Ludwig, Monopole der Gewalt. Mafiose Macht, staatliche Souveränität und Wiederkehr normativer Theorie, Bielefeld: Transcript Verlag, 2003.

HRUSCHKA, Joachim, Strukturen der Zurechnung, Berlin: Walter de Gruyter, 1976. 
Polít. crim. Vol. 12, № 23 (Julio 2017), Art. 2, pp. 56-77.

[http://www.politicacriminal.cl/Vol_12/n_23/Vol12N23A2.pdf]

JÄGER, Thomas, "Transnationale Organisierte Kriminalität, en: Aus Politik und Zeitgeschichte, Bonn: Bundeszentrale für politische Bildung, 63. Jahrgang 38-39, 2013, pp. 15-21.

JAKOBS, Günther, „Kriminalisierung im Vorfeld einer Rechtsgutsverletzung“, Zeitschrift für die gesamte Strafwissenschaft, Berlin: Walter de Gruyter, vol. 97 (1985), pp. 751785.

KELLY, Robert J., "Criminal Underworlds: Looking Down on Society of Bellow" en: KELLY, Robert J., (Ed.), Organized crime: Cross-Cultural studies, New Jersey: Rowman \& Littlefield, 1986.

KELSEN, Hans, "Will the Judgment in the Nuremberg Trial Constitute a Precedent in International Law?”, The International Law Quarterly, Vol. 1, No. 2 (1947), pp. 153171.

KINDHÄUSER, Urs, Gefährdung als Straftat: rechtstheoretische Untersuchungen zur Dogmatik der abstrakten und konkreten Gefährdungsdelikte, Frankfurt am Main: Klostermann, 1989.

LAMPE, Klaus von, „Was ist ,Organisierte Kriminalität“?“, Aus Politik und Zeitgeschichte, Bonn: Bundeszentrale für politische Bildung, 63. Jahrgang 38-39, 2013, pp. 1-8.

, "The study of organised crime: An assessment of the state of affairs" en: INGVALDSEN, Karsten; LUNDGREN SORLI, Vanja (Eds.), Organised Crime: Norms, markets, regulation and research, Unipub, Oslo, 2009, p. 165-211.

, "Organised Crime Research in Perspective", en: DUYNE, Petrus van; LAMPE, Klaus von; PASSAS, Nikos (Eds.), Upperworld and Underworld in Cross-Border Crime, Nijmegen: Wolf Legal Publishers, 2002, pp. 189-198.

MUÑOZ CONDE, Francisco, “¿Es el Derecho penal internacional un 'Derecho penal del enemigo'?”, Revista Penal, vol. 21 (2008), pp. 93-102.

ROXIN, Claus, Täterschaft und Tatherrschaft. 8. Auflage, Berlin: Walter de Gruyter, 2006. , ,Probleme von Täterschaft und Teilnahme bei der organisierten Kriminalität“" en:

SAMSON, Erich; DENCKER, Friedrich; FRISCH, Peter; FRISTER, Helmut; REI $\beta$, Wolfram (Eds.), Festschrift für Gerald Grünwald zum siebzigsten Geburtstag, Baden-Baden: Nomos Verlagsgesellschaft, 1999, pp. 549-561.

RUDOLPHI, Hans-Joachim, „Verteidigerhandeln als Unterstützung einer kriminellen oder terroristischen Vereinigung i. S. der $\S \S 129$ a StGB“, Festschrift für H.J. Brums zum 70. Geburtstag, Köln: Heymann, 1978, pp. 315-338.

SCHÜTZ, Alfred, El problema de la realidad social: Escritos I, Buenos Aires: Amorrortu, 1974.

, On Phenomenology and Social Relations, Chicago: Chicago University Press, 1973.

SCHÜTZ, Alfred, LUCKMANN, Thomas, Strukturen der Lebenswelt, Konstanz: Verlag C.H. Beck, 2003.

SILVA SÁNCHEZ, Jesús-María, "La 'intervención a través de organización’, ¿una forma moderna de participación en el delito?” en: SILVA SÁNCHEZ, Jesús-María, CANCIO MELIA, Manuel (Eds.), Delitos de organización, Buenos Aires: B de F, 2008, pp. 87-118.

, La expansión del Derecho penal. Aspectos de la política criminal de las sociedades postindustriales, Madrid: Civitas, 1999. 
CORDINI, Nicolás. "Jurisdicción regional y delitos de organización: diversas alternativas".

TRIFFTERER, Otto, Dogmatische Untersuchungen zur Entwicklung des materiellen Völkerstrafrechts seit Nürnberg, Freiburg i.Br.: Albert, 1966.

VOGEL, Joachim, "La internacionalización del Derecho penal y del Proceso penal", Revista penal, vol. 22 (2008), pp. 160-167.

, "Estado y tendencia de la armonización del Derecho penal material en la Unión europea", Revista penal, vol. 10 (2002), pp. 112-129.

WALLERSTEIN, Immanuel, Las incertidumbres del saber, Trads. BARBA, Julieta, JAWERBAUM, Silvia, Barcelona: Gedisa, 2005.

ZAFFARONI, Raúl, et al, Derecho penal: parte general, $2^{\mathrm{a}}$ edición, Buenos Aires: Ediar, 2002. 